\title{
NOVA ESPÉCIE DE GALIUM L. (RUBIACEAE) PARA O ESTADO DE SÃO PAULO, BRASIL
}

Recebido em 25.08.2002. Aceito em 03/06/2003

RESUMO - (Nova espécie de Galium L. (Rubiaceae) para o Estado de São Paulo, Brasil). Uma nova espécie de Rubiaceae, Galium shepherdii Jung-Mendaçolli, procedente da Serra da Mantiqueira, Estado de São Paulo, Brasil, é descrita e ilustrada.

Palavras-chave - Galium, Rubiaceae, espécie nova

ABSTRACT - (A new species of Galium L. (Rubiaceae) from São Paulo State, Brazil). A new species of Rubiaceae, Galium shepherdii Jung-Mendaçolli, from Serra da Mantiqueira, São Paulo State, Brazil, is described and illustrated.

Key words - Galium, Rubiaceae, new species

\section{Introdução}

Como parte dos estudos sobre as Rubiaceae nativas do Estado de São Paulo, foi reconhecida uma nova espécie de Galium L., procedente da Serra da Mantiqueira, coletada em altitude que oscila entre 2.500-2.660m.s.m., onde a vegetação é predominantemente herbáceoarbustiva e o substrato rochoso.

O gênero Galium compreende aproximadamente 400 espécies (Judd et al. 1999), sendo bem representado nas regiões temperadas do hemisfério norte e locais montanhosos dos trópicos (Burger \& Taylor
1993). As plantas são bissexuadas, unissexuadas ou poligâmicas, apresentam hábito herbáceo, caule quadrangular e estípulas geralmente iguais às folhas em forma e tamanho, indistingüiveis das últimas, exceto por não apresentarem gemas axilares; o conjunto de folhas e estípulas, denominado pela maioria dos autores, simplesmente como folhas, apresenta-se como verticilos nos ramos. O protótipo da inflorescência de Galium é uma címula que consiste de uma flor terminal e dois râmulos laterais, os quais podem ou não ramificar-se (Dempster 1982), dando origem a inflorescências que podem ser paniculadas, com 
ramificações dicasiais ou tricotômicas, três flores a partir do nó distal ou flores solitárias. (Burger \& Taylor 1993). A inflorescência padrão do grupo Relbunium - ao qual pertencem as espécies de Galium da América do Sul, América Central, Sudoeste dos Estados Unidos e ilhas do Caribe - consiste de pedúnculo originado de uma axila foliar, encimado por quatro brácteas involucrais foliáceas e uma única flor séssil (Dempster 1990). As flores podem ser bissexuais ou unissexuais, muito pequenas (1-4mm diâm.); cálice diminuto ou ausente; corola rotada a campanulada ou urceolada, amarela, verde, rosa ou vermelha; estames geralmente alternos às pétalas, anteras versáteis, exsertas; ovário 2-locular, 1 óvulo por lóculo, estiletes 2 , às vezes ausentes nas flores funcionalmente estaminadas, estigmas capitados. Fruto bacáceo, variando de carnoso a relativamente seco, geralmente 2-lobado, separando-se em dois "mericarpos" 1-seminados. Semente convexa dorsalmente (Dempster 1990; Burger \& Taylor 1993). São conhecidas 23 espécies de Galium no Brasil (Dempster 1980; 1981; 1982; 1990). A descrição desta nova espécie elevará para nove o número de espécies ocorrentes no Estado de São Paulo e 24 para o Brasil.

\section{Descrição e discussão}

Galium shepherdii Jung-Mendaçolli, sp.nov. Fig. 1, a-f

Galium shepherdii Jung-Mendaçolli proxime accedit ad G. hatschbachii Dempster corolla pro ratione magna $(3,5-4,0 \mathrm{~mm}$ et $4,0 \mathrm{~mm}$ diam. secundum individua) tamen ab ea differt internodiis brevioribus, foliis minoribus, 1-2 pedunculis in unoquoque nodo, foliis inclusis, lamina ovali-lanceolata, raro elliptica nervisque secundariis non visibilibus.

Erva decumbente; ramos glabros, lenhosos na base, quadrangulares, sub-alados, internós curtos, 1,5-4mm compr.; folhas subsésseiss, 4-verticiladas; lâmina 5-6×3-4mm, oval-lan- ceolada, raro elíptica, ápice agudo, desprovido de múcron, base cuneada, margem revoluta, crassa, glabra, face adaxial brilhante, olivácea a nigrescente in sicco, 1-nervada, nervuras secundárias não observáveis. Flores 1-2 por axila, inclusas nas folhas, bissexuais; brácteas involucrais 4 , ligeiramente desiguais, ca. $2,5 \mathrm{~mm}$ compr., elíptico-lanceoladas ou obovallanceoladas, ápice agudo a arredondado; pedúnculo ca. 2,0mm compr.; corola rotada, amarelo-esverdeada, 4-6-mera, 3,2-4mm diâm., pétalas $1,6-1,8 \times 0,8-1,0 \mathrm{~mm}$, triangulares a lanceoladas, ápice agudo, com glândulas vináceas dispostas em duas linhas laterais e uma mediana; flor estaminada (?): estames sempre 4, ca. $0,8 \mathrm{~mm}$ compr., filetes filiformes, ca. $0,4 \mathrm{~mm}$ compr., anteras suborbiculares, pólen presente; lóculos do ovário 1(-0) ovulados, estigmas 2, sésseis. Frutos não observados.

Tipo: BRASIL: São Paulo: Queluz, Serra da Mantiqueira, crista da montanha vizinha à Pedra da Mina, entre $22^{\circ} 25^{\prime} 53^{\prime \prime}$ e $22^{\circ} 26^{\prime} 08^{\prime \prime}$ 'S e $44^{\circ} 50^{\prime} 05^{\prime}$ 'W, altitude $2.500-2.660 \mathrm{~m}, 18 / \mathrm{II} / 1997$, fl., G.J. Shepherd, 97-51, R. Goldenberg, R. Belinello, J.C. Galvão \& Santos (Holótipo UEC, Isótipo IAC).

A corola relativamente grande aproxima G. shepherdii de G. hatschbachii (3,5-4mm e 4,0mm diâm., respectivamente). Entretanto, a análise de parátipos desta última (G. Hatschbach 43217, G. Hatschbach 20822 \& J. P. Fontella), evidencia internós maiores (1,0-9,0cm compr.), folhas mais longas (até $1,4 \mathrm{~cm}$ compr.), lâmina estreitamente elíptica ou oblanceolada e nervuras secundárias conspícuas e geralmente quatro pedúnculos por nó, nitidamente exsertos. G. hatschbachii tem sua ocorrência assinalada para os Estados do Paraná (municípios de São José dos Pinhais, Uberaba de Baixo e Roseira) e Santa Catarina (Campo Alegre e Joinville), crescendo em capões e bordas de florestas.

Ainda como observação final, G. shepherdii é facilmente reconhecida pelos internós bastante encurtados, conferindo um aspecto contraído à planta, e pelos pedúnculos 

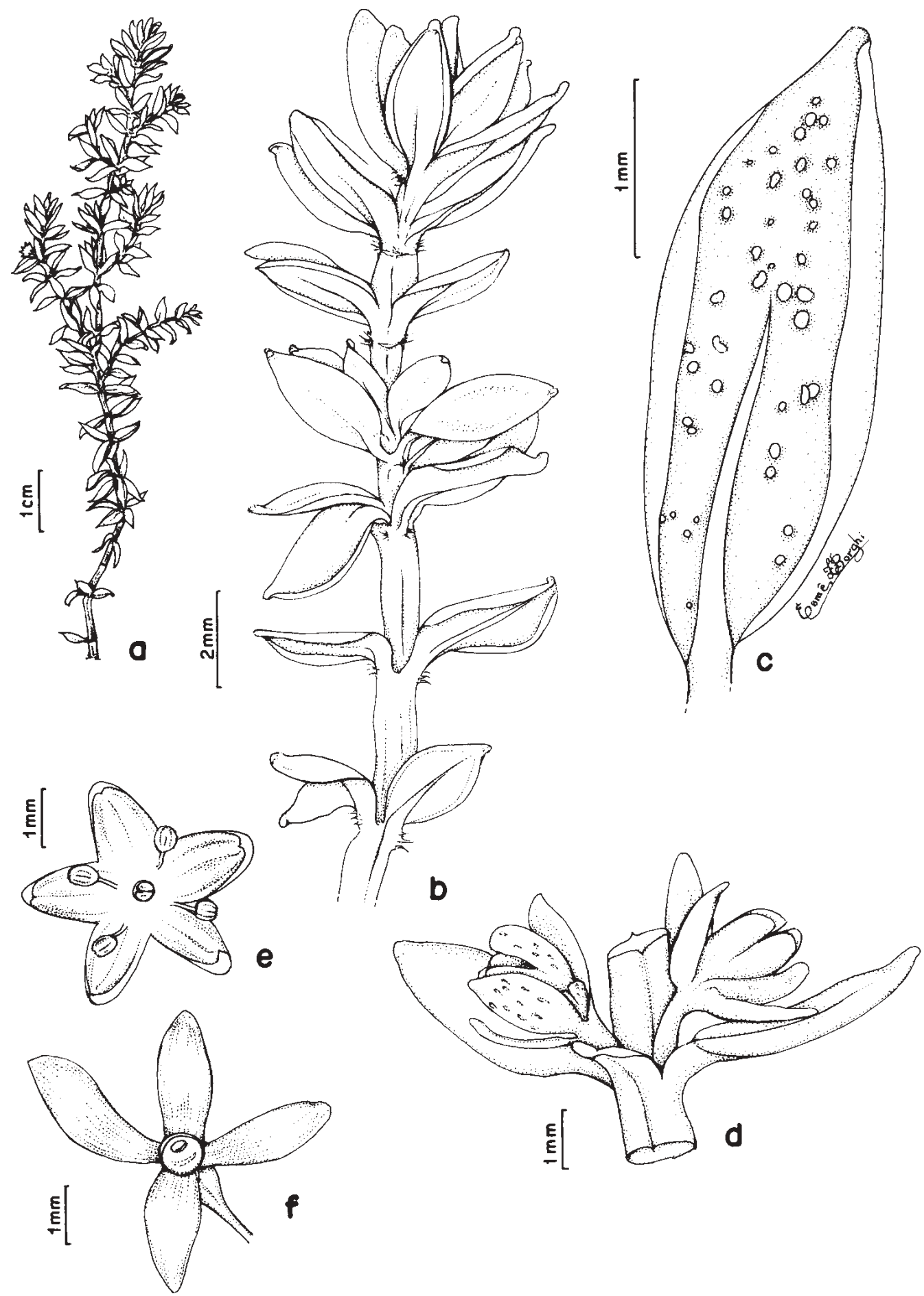

Figura 1. Galium shepherdii Jung-Mendaçolli: a. aspecto geral de ramo; b. detalhe de ramo estéril; c. detalhe da face abaxial de folha evidenciando glândulas translúcidas e sua distribuição; d. detalhe de um nó com flores; e. corola de flor bissexual, evidenciando estames, e na região central, os estigmas sésseis; f. brácteas involucrais, evidenciando o ovário na região central e região de inserção dos estigmas. (Shepherd et al. 97-51) 
curtos, ocultando as flores entre os verticilos foliares.

\section{Agradecimentos}

Aos herbários BAUR, BOTU, ESA, FFCL, FUEL, HB, HRCB, ICN, ISA, IF, MBM, P, PMSP, R, RB, S, SJRP, SP, SPF, SPFR, SPSF, UEC, UB e Gray Herbarium, por possibilitarem a consulta e/ou o empréstimo de materiais botânicos de espécies de Galium e que permitiram a certeza do reconhecimento da nova espécie aqui tratada; à FAPESP e ao CNPq, pelo auxílio e bolsa de produtividade concedidos; à Profa. Neusa M. Monteferrante, responsável pelas cadeiras de Língua Latina e Literatura Latina da Universidade São Marcos, pela redação da diagnose; à bióloga e bolsista da FAPESP, Luciane Perosin Cabral, pela colaboração nos trabalhos referentes ao gênero Galium durante o período de seu estágio no IAC.

\section{Referências bibliográficas}

Burger, W. \& Taylor, C.M. 1993. Rubiaceae. In Flora Costaricensis (Burger, W. ed.). Fieldiana: Botany, New Series 33: 1-333.

Dempster, L.T. 1980. The genus Galium section Lophogalium (Rubiaceae) in South America. III. Allertonia 2(4): 247-279.

Dempster, L.T. 1981. The genus Galium (Rubiaceae) in South America. II. Allertonia 2(8): 393-426.

Dempster, L.T. 1982. The genus Galium (Rubiaceae) in South America. III. Allertonia 3(3): 211-258.

Dempster, L.T. 1990. The genus Galium (Rubiaceae) in South America. IV. Allertonia 5(3): 283-345.

Judd, W.S.; Campbell, C.S.; Kellogg, E.A. \& Stevens, P.F. 1999. Plant systematics - a phylogenetic approach. Sinauer Associates, Inc., Massachusets. 